Pedagogía y Saberes n. ${ }^{\circ} 53$ Universidad Pedagógica Nacional

Facultad de Educación. 2020. pp. 53-68

\title{
Antropología pedagógica: de las imágenes del hombre a la búsqueda de sentido*
}

\section{Artículo de investigación}

Pedagogical Anthropology: from Man's Images to the Search for Meaning

Antropologia pedagógica: das imagens do homem para a busca de sentido

\section{Liliana Saavedra Rey** Sneider Saavedra Rey***}

\section{Para citar este artículo:} Pedagogía y Saberes, 53, 53-68. https://doi.org/10.17227/pys.num53-10567

* Artículo derivado de las investigaciones "Incidencia de la evaluación en la formación de niños y niñas entre cuatro y siete años" y "La creación literaria como despliegue estético para la formación humana”, pertenecientes a la línea de Antropología Pedagógica del grupo Tendencias Actuales en Educación y Pedagogía (TAEPE) de la Facultad de Humanidades y Ciencias de la Educación de la Universidad de San Buenaventura, sede Bogotá.

** Doctora en Humanidades, Humanismo y Persona de la Universidad de San Buenaventura, Bogotá, Colombia. Coordinadora de investigaciones de la Universidad de San Buenaventura, Bogotá, Colombia. Miembro del grupo Tendencias Actuales en Educación y Pedagogía (TAEPE).

Correo electrónico: lsaavedra@usbbog.edu.co

ORCID: https://orcid.org/0000-0003-0326-2738

*** Doctor en Humanidades, Humanismo y Persona de la Universidad de San Buenaventura, Bogotá, Colombia. Profesor investigador de la Universidad de San Buenaventura y director académico del Programa de Años Intermedios (PAI) del Bachillerato Internacional (IB) en Gimnasio Los Portales, Bogotá, Colombia. Miembro del grupo Tendencias Actuales en Educación y Pedagogía (TAEPE).

Correos electrónicos: alsaavedra@usbbog.edu.co; a.saavedra@losportales.edu.co

ORCID: https://orcid.org/0000-0002-6616-760X 


\title{
Resumen
}

En el marco de la tradición alemana y sus ciencias del espíritu, la antropología pedagógica se enfoca en el ser humano en cuanto es educable (homo educandus) de acuerdo con su apertura al mundo y condición dúctil (formabilidad), para así lograr tanto su socialización (educación) como su personalización (formación). A pesar de la importancia de estos propósitos de humanización para cualquier práctica educativa, esta disciplina ha tenido una difusión limitada en la discusión pedagógica en Colombia, debido al interés instrumental en los componentes del sistema educativo, obviando así al ser humano real que se pretende formar. En respuesta, este artículo de investigación plantea la relevancia de esta disciplina para el campo conceptual de la pedagogía desde su análisis histórico; sus fundamentos antropológicos y pedagógicos centrados en el anthropos como un ser de mediaciones, perfectible y simbólico; y sus objetivos de educar y formar desde las imágenes del hombre, hasta actualizarlos en el sentido singular que cada persona en sus circunstancias concretas construye en el despliegue de su existencia.

\section{Palabras clave}

antropología pedagógica; antropología; pedagogía; educación; formación (Bildung)

\begin{abstract}
In the German tradition and its sciences of the spirit, the pedagogical anthropology focuses on human as an educable being (homo educandus) according to his opening to the world and malleable condition (formability), in order to achieve both socialization (education) and personalization (formation). Despite the importance of these humanization purposes for any educational practice, this discipline has had limited dissemination in pedagogical discussion in Colombia, because of the instrumental interest in educational system components, omitting in this way the real human being pretended to be educated. In response to this situation, this research article sets out the relevance of this discipline for the pedagogical conceptual field based on its historical analysis; its anthropological and pedagogical principles focused on the anthropos as a being of mediation, perfectible and symbolic; and its objectives of educating and forming from the images of man until updating them in the unique meaning sense that each person in his concrete circumstances builds on the unfolding of his existence.
\end{abstract}

\section{Keywords}

pedagogical anthropology, anthropology, pedagogy, education, formation (Bildung)

\section{Resumo}

No contexto da tradição alemã e suas ciências do espírito, a antropologia pedagógica se enfoca no ser humano com um ser educável (homo educandus) de acordo com a sua abertura para o mundo e condição dúctil (formabilidade), para assim alcançar tanto sua socialização (educação) como sua personalização (formação). Apesar da importância desses propósitos de humanização para qualquer prática educativa, essa disciplina tem tido uma difusão limitada na discussão pedagógica na Colômbia, devido ao interesse instrumental nos componentes do sistema educativo, evitando assim o ser humano real que se pretende formar. Em resposta, este artigo de pesquisa apresenta a relevância dessa disciplina para o campo conceitual da pedagogia desde sua análise histórica; seus fundamentos antropológicos e pedagógicos centrados no anthropos como um ser de mediações, perfectível e simbólico; e seus objetivos de educar e formar a partir das imagens do homem, até atualizá-los no sentido único de cada pessoa em suas condições concretas constrói na instalação da sua existência.

\section{Palavras chave}




\section{Introducción}

Más allá de los procesos históricos que la han constituido conceptualmente, como producto de la modernidad, "la educación existe porque nacemos" (Arendt, 1954, citada por Campo y Restrepo, 2000), independientemente de las tradiciones que en Occidente han legado diversas maneras de configurar su campo pedagógico. De hecho, la educación ha pervivido ligada a la vida de los hombres mediante un propósito de humanización que implica que cada persona "asuma en su vida su propia dirección racional, reconociendo fraternalmente a sus semejantes el mismo derecho y la misma dignidad" (Flórez, 2001, p. 111). Esta idea mantiene el objetivo que concibió Kant (2008) para ella como "el único medio para alcanzar la plenitud humana", dando "forma a las disposiciones y capacidades naturales del hombre" (Gadamer, 2012, p. 39), por lo cual puede considerarse el tema humano de mayor importancia para la filosofía moderna.

Como lo hemos planteado en otro lugar (Saavedra y Saavedra, 2013, 2017), la educación es un proceso permanente de formación y crecimiento de las personas en un contexto social determinado para su endoculturación, desarrollo orgánico y despliegue espiritual. Por ello, no se realiza en lo indeterminado sino en la vida concreta, en un nicho social y una cultura específica, consolidando la manera en que las personas se conciben a sí mismas, valoran y actúan, indicando y promoviendo la evolución de la sociedad. Ella es, en sí misma, un perenne trasegar social que está en constante transmutación para afrontar problemas emergentes de la realidad del hombre. Ávila (1994) afirma que la educación media entre la pedagogía y la cultura, pues se hace posible por la sociedad y recibe de esta su apoyo e influencia. Es en el ámbito de la pedagogía donde adquiere su plena dimensión significativa y todo su soporte y proyección epistemológicos, debido a la "lógica profesional que subyace a la producción del discurso pedagógico" (Ávila, 1994, p. 126). De hecho, hablar de educación sin pedagogía es hacer perder a la primera la dirección y validez reconstructivas en términos humanos, académicos, culturales y sociales. En cambio, el reconocimiento de su correlación permite superar los límites impuestos por diversos intereses sociales, con el fin de lograr la perpetuación de la cultura y su reconstrucción como propósitos fundamentales.

Ya lo había considerado Durkheim (2001) cuando afirmó que "el único medio de impedir que la educación caiga bajo el yugo de la costumbre y degenere en automatismo maquinal e inmutable, es el de tenerla siempre despierta, mediante la reflexión" (Durkheim, 2001, p. 120). También Runge (2008), parafraseando a Klafki, ha planteado que "sin reflexión pedagógica, todo intento didáctico o metódico se vuelve sospechoso, sospechoso de impulsar acríticamente las urgencias sesgadas de una época" (Runge, 2008, p. 182). La tarea insoslayable de la pedagogía es la reflexión sobre los procesos evolutivos de la educación, pues aquella "comienza cuando uno toma cierta distancia de ella y se pregunta por su naturaleza y sus funciones" (Ávila, 1990, p. 58). Esto implica, para los maestros, el compromiso de mantener una posición activa, desde la pedagogía, para afianzar la identidad profesional y la pertinencia de su acción formativa a través de los conocimientos aportados en su devenir por las ciencias, las artes y la filosofía.

Sin embargo, en el seno de la "instrumentalización del saber pedagógico" (Zuluaga et al., 2003), este se confunde con todo lo que puede ser enseñable. Bajo el rótulo de lo pedagógico han proliferado múltiples discursos, hasta llegar a pedagogías light o fashion, de acuerdo con el gusto de los consumidores, según ha planteado Noguera (2008). Este mismo autor determina al menos tres acepciones que en Colombia han permitido tal eclosión de modas pedagógicas: la pedagogía como todo lo que es deseable socialmente, de donde se derivan pedagogías de la paz, la felicidad, el ocio, el cuerpo, el trabajo, la esperanza, la diferencia, etc.; pedagogías de acuerdo con los sujetos, usuarios o destinatarios de la educación, esto es, de oprimidos, infancia, tercera edad, feministas, comunitarias, entre otras; y finalmente, pedagogías según su calidad o filiación: críticas, participativas, nuevas, tradicionales, innovadoras, poscoloniales, constructivistas, interculturales, solo por mencionar las más recurrentes (Noguera y Parra, 2015). Si a este desarrollo azaroso de la pedagogía en el país se suma la evolución histórica de las tradiciones pedagógicas modernas (francófona, germana, anglosajona) que han constituido saberes altamente especializados y trazado límites teóricos de acuerdo con proyectos de formación desde lo nacional hacia el mundo occidental, se concreta un escenario de alta complejidad en el que es necesario situarse para adelantar cualquier acción educativa fundamentada, reconociendo las diversas vertientes disciplinares que han contribuido en su evolución conceptual.

Este es el caso de las ideas pedagógicas que durante los siglos XVIII y XIX tomaron forma desde la institucionalidad académica y las orientaciones de naciones particulares, lo cual es abordado por Noguera (2012) como tradiciones pedagógicas. En primer lugar, la tradición germánica ocupada del problema de la Bildung (formación), en cuanto autorrealización espiritual de las personas -el cultivo personal como ideal estético- inspirada en el humanismo y el 
Romanticismo alemanes (Horlacher, 2014a, 2014b). Sus distinciones conceptualizaron la pedagogía como interesada en la educación general mientras dejaron a la didáctica su énfasis en los procesos específicos de enseñar y aprender. En segundo lugar, la tradición francófona que, subordinando la pedagogía a disciplinas como la sociología o la psicología, desarrolló las Ciencias de la Educación que han reinterpretado el campo pedagógico - ¿enriqueciéndolo? ¿atomizándolo?-, privilegiando conceptos como poder o aprendizaje, en detrimento de los cuestionamientos generales de la educación. Finalmente, en la tradición anglosajona, conceptos como currículo y competencia aparecen como un discurso nuevo, sin tradición aparente, generando nociones plásticas que, en consecuencia, pueden ser utilizadas en diversas situaciones, con múltiples significados y sentidos. Sin duda, un rasgo más de esa flexibilidad social propia de la globalización y el neoliberalismo (Saavedra y Saavedra, 2017).

En este contexto, este artículo comprende la pedagogía como un campo de reflexión sobre la educación y la cultura, con el fin de profundizar en su perspectiva antropológica, derivada de las ciencias del espíritu de la tradición pedagógica alemana. En cuanto disciplina, esta antropología pedagógica viene a formalizar las relaciones del pensamiento pedagógico con el antropológico, existentes incluso desde antes de que nacieran estas denominaciones como producto de la Modernidad, pues evidencian la relación insoslayable y mutua entre el conocimiento sobre el hombre y su posibilidad de educarlo y formarlo. Especialmente en Alemania en el siglo XX, esta se enfocó en el ser humano en su proceso de realización (homo educan$d u s$ ) en cuanto deudora de la antropología filosófica y su sustrato espiritual. Como en nuestro país esta disciplina aún no goza de la difusión suficiente ${ }^{1}$, con este trabajo buscamos contribuir a las discusiones en este campo, muchas veces más centradas en los vericuetos de un sistema educativo cosificado, que en las personas a las que piensan educar y formar (Saavedra, 2016). Nuestro fin último es, entonces, profundizar en la comprensión de lo humano -de las imágenes del hombre a la construcción de sentido singular de cada persona- como base ineludible de cualquier planteamiento pedagógico.

1 Más allá del trabajo sostenido que durante dos décadas ha realizado el Grupo sobre Formación en Antropología Pedagógica e Histórica (FORMAPH) de la Universidad de Antioquia, y la línea de investigación en Antropología Pedagógica. Persona y formación tanto del Grupo Tendencias Actuales en Educación y Pedagogía (TAEPE) como del reciente Doctorado en Humanidades, Humanismo y persona de la Universidad de San Buenaventura, entre otros esfuerzos individuales de maestros e investigadores

\section{Pedagogía, educación y formación en la tradición pedagógica alemana}

En su configuración e institucionalización como campo disciplinar y académico, la tradición pedagógica alemana construye desde el pensamiento filosófico, especialmente desde las comprensiones derivadas de la Ilustración, el idealismo y las ciencias del espíritu, la idea de la educación en su dimensión histórica, como vivencia humana. En Ensayos sobre pedagogía alemana, Runge (2008), quizá el mayor conocedor de esta tradición en el país ${ }^{2}$, define la pedagogía desde esta línea de pensamiento.

Utilizamos la expresión "pedagogía" en un sentido equivalente al de "ciencia de la educación" y, en cierta medida, al de "ciencias de la educación" [...] para designar un ámbito disciplinar, académico $e$ institucional en el que se tratan asuntos referidos a la educación y ligados a ella como la enseñanza, la instrucción, el aprendizaje y la formación. Es decir, utilizamos la expresión pedagogía como nombre general para designar un campo disciplinar de estudio e investigación que se institucionalizó y academizó durante el siglo xviII [...] y que en tradiciones como la alemana cuenta con un claro reconocimiento como parte de las ciencias sociales y humanas. Entendemos entonces por pedagogía un campo disciplinar, plural y abierto que obedece, precisamente, a la complejidad de su asunto tratado: la educación. De acuerdo con esto último, la pedagogía se puede entender, a la vez, como un campo disciplinar teórico y práctico (especulativo, descriptivo, experimental y normativo). Teórico, en cuanto en ella se producen conocimientos especulativos sobre la educación (historia, sociología, antropología, filosofía de la educación); conocimientos a partir de los cuales se busca dar claridad y entender los problemas de la educación, tratando de describirla, explicarla, comprenderla (qué es la educación, por qué y cómo los hombres se perfeccionan por ella, cuáles son sus aspectos antropológicos, cómo se ha dado en las sociedades y en la historia). Pero

2 En cuanto al estudio específico de la pedagogía alemana en el país es importante resaltar el aporte realizado por la revista Educación y Pedagogía de la Universidad de Antioquia que desde 1991 ha realizado traducciones de autores como Wolfgang Klafki, Winfried Bohn, Helmut Fend, Otto Friedrich Bollnow o Rudolf Vierhaus, entre otros, con el fin de introducirlos al contexto nacional. Este interés por la tradición pedagógica alemana y sus conexiones con nuestro país impulsó la realización del Primer Simposio Colombo-Alemán en 1999 en Medellín, y la publicación posterior del libro Encuentros pedagógicos transculturales: desarrollo comparado de las conceptualizaciones y experiencias pedagógicas en Colombia y Alemania (Universidad de Antioquia, 2001). 
es igualmente un campo disciplinar práctico en la medida en que en él también se producen reflexiones, conocimientos, experiencias y propuestas aplicadas que se refieren y se dirigen a la praxis -educación, enseñanza, a las prácticas de crianza-, con el propósito de justificarla (qué hace educadora a una acción, qué significa y cómo se justifica una acción educativa correcta y legítima), mejorarla, cualificarla, hacerla formativa, etc. (Runge, 2008, pp. 30-31)

Esta definición esclarece la doble dimensión de la pedagogía, constituida por la teoría y la práctica, que remite tanto al conocimiento científico e histórico como a aquellos saberes pedagógicos que surgen de la experiencia educativa. Además, plantea que dicha praxis es el objeto de estudio de la pedagogía en el marco más amplio "del conocimiento en la interioridad de una cultura" (Zuluaga et al., 2003, p. 36). Y es que, en palabras de Wulf (1985), "la pedagogía es una lectura del mundo más que un dispositivo de dominación, se trata de una concepción sobre el mundo, el hombre, la sociedad, la infancia, la escuela, el conocimiento, entre otros" (citado por Echeverri, 2013, p. 3).

La pedagogía identifica como su objeto de estudio a la educación, campo de apertura social y de problematización de pensamiento que promueve tanto la apropiación del legado cultural como la reconstrucción del conocimiento, de manera que transforma las condiciones de vida de las personas y sus comunidades. De acuerdo con Dilthey (1940), Spranger (1935) o, en el contexto latinoamericano, Luzuriaga (1991), se puede afirmar que la pedagogía es una "ciencia del espíritu o de la cultura" que estudia la educación como una parte de la realidad humana y contesta a preguntas como: ¿Qué es la educación?, ¿cómo debe ser la educación?, ¿cómo debe realizarse la educación?, relacionándolas con la vida individual y social de las personas.

En el seno de la tradición pedagógica alemana la educación es una praxis, un hacer. Teniendo en cuenta que la pedagogía reflexiona o investiga sobre este hacer, Benner (1996, citado por Runge, 2008) ha planteado el concepto de praxeología, que esclarece la relación entre lo pedagógico y las distintas formas de praxis social que constituyen la cultura. En ella, las personas se enfrentan a tres situaciones problemáticas humanas fundamentales: confrontación entre ellos mismos, derivando asuntos de organización, regulación, gobierno, etc.; confrontación entre ellos y la naturaleza, que se configura en la conservación y el dominio del medio propio del trabajo, la ciencia o la técnica; e interiormente, debido a la imperfección como rasgo propio de la condición humana y a la formabilidad contenida en todo hombre. En este último conflicto, su apertura al mundo lo enfrenta con su propia fragilidad y finitud. De acuerdo con Runge (2008),

Así, dentro de la complejidad de la praxis social conjunta, la práctica educativa o educación aparece entonces, a la vez, como una forma de autoconservación humana, de humanización, que se ha enfocado fundamentalmente en el trabajo sobre el "desvalimiento" (Pestalozzi) y no formación de las nuevas generaciones -"el ser humano solo puede devenir humano mediante la educación” (Kant)- y, a nivel de la dinámica social misma, como una estrategia social para autorreproducirse y establecer dinámicas de mediación. Así pues, mediante la educación se le ayuda a las nuevas generaciones a su supervivencia (socializándolas, culturizándolas, educándolas, instruyéndolas) en sociedad y se regula, en términos micro y macrosociales, el proceso de cambio y relevo generacional, manteniéndose con ello la existencia misma de la sociedad [...]. Así pues, desde el punto de vista praxeológico, el ser humano es concebido como un ser que actúa, interactúa y trabaja, como un ser que experimenta constantemente y que se compromete con su propio actuar que tiene lugar tanto en el mundo de lo simbólico como en el de lo histórico y cultural. (p. 35)

De esto se deriva que, cronológicamente, la educación antecede a la reflexión sistemática sobre ella. "Por lo tanto, la educación como una praxis social ni surge con la reflexión pedagógica, ni el saber que en ella se produce-saber hacer-es un saber exclusivo de esta última" (p. 35). De hecho, para especificar su significado y sentido, Runge (2008) ensaya la siguiente definición orientadora sobre esta praxis:

La educación o práctica educativa es la actividad —o el conjunto de actividades - o simplemente la praxis en la que la instancia A (maestro, profesor, tutor, sabio) en el marco de unas orientaciones que bien pueden ser implícitas o explícitas (para qué) y de unas circunstancias específicas (aspectos sociales, culturales, locativos), pretende y trata de influir sobre una instancia B (alumno, adulto, aprendiz, grupo) de un cierto modo (cómo) con el propósito (con qué fin) de que esa instancia B se transforme, bien sea al apropiarse de unos contenidos (qué) y/o al cambiar su forma de ser (con el propósito de que mediante ese cambio, ese devenir algo otro, se forme -Bildung-). (p. 38)

Esta distinción entre Bildung (formación) y Erziehung (educación), que fue originalmente planteada por Herbart (1990), ha suscitado múltiples estudios de base etimológica y filosófica en los últimos años (Garcés y Runge, 2011; Horlacher, 2014a, 2014b; Fabre, 2011; Vierhaus, 2001; Ipland, 1999) debido a 
que se desarrolla en el seno de una lengua, una cultura y una tradición pedagógica específicas. Este autor pionero diferencia con claridad la idea de formación (Bildung) de la educación, pues esta última atañe a la adaptación de las personas a unas condiciones dadas, mientras la primera revela un proceso de despliegue del ser humano. Así se reconoce que el hombre no nace determinado -como lo pretende el sistema educativo que define lo que es importante de aprender y lo que no-, sino que se determina y se forma en su despliegue como persona, durante su propia existencia (Saavedra, 2020).

La formación, entonces, "designa el modo específicamente humano de dar forma a las disposiciones y capacidades naturales del hombre" (Gadamer, 2012, p. 39) de manera impredecible o contingente. No se puede determinar por unos objetivos de clase, un profesor, un currículo, una institución o un sistema escolar, más allá de que estos puedan y deban influir en dicho proceso. En efecto, la formación no elimina el papel del maestro. Por el contrario, requiere de un encuentro con el otro, así como con lo otro que hay en uno mismo, para lograr la realización personal, pues "reconocer en lo extraño lo propio, y hacerlo familiar, es el movimiento fundamental del espíritu, cuyo ser no es sino retorno a sí mismo desde el ser otro" (Gadamer, 2012, p. 43). Es decir, la Bildung enfatiza en el proceso de constantes transformaciones (conversiones) que atraviesan las personas durante su existencia, en el encuentro y la apropiación de lo extraño del mundo, de lo otro y los otros, para abrirse a sí mismos, en aras de su propia proyección. Sin duda, tales cambios superan, trascienden o al menos modifican en diferentes grados los ideales educativos planteados desde el exterior.

Si bien la Bildung se configura en el debate educativo del siglo XVIII, se han evidenciado sus conexiones con la paideia griega (Vilanou, 2001), pues el marco de la filosofía antigua como modo de vida implicó una articulación de la cultura y la educación como parte de "la estructura histórica objetiva de la vida espiritual de una nación" (Jaeger, 2001, p. 2). De modo más amplio, estos estudios han concluido que la formación es un concepto íntimamente vinculado a la evolución humana en toda su historia, desde "los protoorígenes del hombre" pues "la necesidad formativa proviene de una lógica interna, de una dialéctica del concepto con la existencia humana" (Ipland, 1999, p. 49). En particular, su devenir desde el misticismo de la Edad Media supone "reconstruir en cada persona la imagen de lo divino que lleva en sí" (Aranguren, 2004, p. 36); su cultivo personal. Precisamente, el idealismo alemán renueva su significado místico en cuanto vida elevada a la que el ser humano aspira.
La palabra alemana Bildung remite a imagen (Bild), modelo (Vorbild), imitación (Nachbild). Es una síntesis y, a la vez, una superación de Form (forma), Kultur (cultura) y de Aufklarung (Ilustración). El origen de la Bildung se sitúa en la mística medieval en la que el hombre lleva en su alma la imagen (Bild) de Dios, a partir de la cual ha sido creado y la cual debe desarrollar. En el siglo XVIII la idea de Bildung se separa progresivamente del antiguo concepto de forma exterior natural (una formación montañosa, un rostro bien formado) para espiritualizarse y asociarse a Kultur, bajo la influencia de Herder y Wilhelm von Humboldt. (Fabre, 2011, p. 216)

Evidentemente, este último autor fue quien planteó con mayor profundidad la dimensión ética de la formación, derivada de la idea kantiana del hombre como único ser educable, quien tiene como deber cultivar sus propios talentos, esto es, realizar una versión mejorada de sí mismo. Refiere "a algo más elevado y más interior, al modo de percibir que procede del conocimiento y del sentimiento de toda la vida espiritual y ética y se derrama armoniosamente sobre la sensibilidad y el carácter" (Humboldt, citado por Gadamer, 2012, p. 39). Precisamente, el contacto de esta idea con el neohumanismo es el que influye de manera determinante en el campo pedagógico y en las ciencias del espíritu, tal como lo planteara Gadamer (2012): "el concepto de la formación que entonces adquirió su preponderante validez fue sin duda el más grande pensamiento del siglo XVIII, y es este concepto el que designa el elemento en el que viven las ciencias del espíritu" (p. 37).

Este sentido moderno - espiritual — con el que se difunde este concepto por todo el mundo debido a las consabidas influencias de Alemania en cuestiones filosóficas y pedagógicas, solo se desarrolla en este país vinculado al pietismo, con su particular idea de experiencia religiosa personal. Este movimiento luterano relaciona la apariencia exterior con el interior humano (su alma) pues desde la autoobservación y la autorreflexión personal se busca la comprensión del mundo y de la naturaleza. Dicho énfasis en la autoformación se vinculó al desarrollo de un estilo o manera de vivir (una estética) que cada persona proyecta ante sí misma para realizarse dentro de sus múltiples posibilidades de existencia. Ese "llegar a ser lo que se es" que Nietzsche (2002) retoma de la consabida sentencia de Píndaro para plantear el despliegue espiritual de cada persona en particular, como efecto, no consecuencia, de la acción educadora (Larrosa, 2013). Así pues, este concepto "se centra principalmente en los procesos internos y no puede describirse como educación en el sentido de crianza o capacitación. Bildung tampoco es conocimiento; 
en cambio, describe una autocomprensión estética con una pretensión de verdad y bondad" (Horlacher, 2014a, p. 38). Por esta razón, este ideal se convirtió en el símbolo de esta época, abordado, además del pietismo, por la Ilustración y el Sturm und Drang, con todo el impacto y la difusión derivados para el mundo de las ideas y las artes, de corte claramente neohumanista y romántico.

En suma, la tradición pedagógica alemana ha configurado los conceptos de formación (Bildung) y educación (Erziehung) para ocuparse, respectivamente, de la formabilidad y la educabilidad. La primera, entendida como ductilidad en cuanto condición específicamente antropológica, a través de la cual el hombre se transforma interiormente de acuerdo con las influencias del exterior, las cuales incorpora o ante las cuales reacciona, elaborando nuevas estructuras espirituales que lo personalizan y socializan. Gracias a esta condición, la educabilidad refiere al proceso de socialización para adquirir la cultura en el plano de las interacciones sociales. Tal es el marco general en que se desarrolla la antropología pedagógica en el siglo xx en Alemania, la cual se enfoca en el hombre como ser formable de acuerdo con su espíritu y su consecuente apertura al mundo.

\section{Antropología pedagógica: educación y formación para el homo educandus}

La antropología pedagógica aborda, de manera distintiva e integrada, dos procesos fundamentales de la vida del hombre: educación y formación, por medio de los cuales el ser despliega, instruye, ejercita, realiza y consolida tanto sus capacidades biológicas como sus disposiciones espirituales, humanizándose. Así, atiende al doble carácter fundamental del anthropos planteado por Kant (1978, citado por Scheuerl, 1985), tanto el fisiológico, de lo que la naturaleza hace de él, como el pragmático, "de lo que él en cuanto ser que actúa libremente hace, o puede hacer, de sí mismo" (p. 10). En este sentido, aborda el homo educandus, abierto, no especializado, carente desde su nacimiento, para contribuir en su comprensión pedagógica y abordaje educativo a lo largo de su existencia, pues justamente estudia las tensiones entre el ser (imagen del hombre) y su devenir específico (construcción de sentido personal) con el fin de desarrollar tanto su socialización como su personalización.

Para ello, esta disciplina se configura, por una parte, a través de los conocimientos proporcionados por las ciencias del hombre como fundamento para la reflexión pedagógica y su consecuente acción educativa; y la manera en que esta praxis contribuye a profundizar la concepción y, sobre todo, el sentido de ser humano, por otra. Por estas vías, de acuerdo con Hamman, responde a dos preguntas (1992, p. 36): “¿Qué enseñan las acciones y circunstancias educativas sobre la esencia del hombre?" (conocer al hombre a través de la educación, mediante la cual se realiza) y “¿qué se deduce del modo humano de ser y de vivir para entender la educación?" (conocer la educación desde la realidad del hombre, determinada por sus condiciones). Estos dos ámbitos son precisados aún más por Dienelt (1980), al plantear como propósito de esta área fundamental de la pedagogía la "determinación esencial del homo educandus" como punto de partida para "el esclarecimiento de la comprensión del fenómeno educativo" (p. 183). Como tal sujeto de estudio -el homo educandus- se caracteriza por su "variabilidad ontológica y posibilidad de configuración creadora del mundo y de sí mismo" (Roth, 1965, citado por Dienelt, 1980, p. 104), la antropología pedagógica configura un camino medio entre la pedagogía filosófica que proporciona fundamentación general sobre el ser humano y sus ideales formativos, y "la penetración filosófica en los fenómenos concretos mismos" para comprender la praxis educativa en sus circunstancias particulares (Bollnow, 2005).

Así, la pregunta por excelencia de cualquier acercamiento antropológico - ¿qué es el hombre?"cuyo desarrollo establece semejanzas y, especialmente, distinciones con respecto a otras especies animales, adquiere dimensión pedagógica cuando indaga por el proceso de realización del ser humano en general y, especialmente, de cada persona concreta en sus circunstancias. Igualmente, la pedagogía, en cuanto reflexión sistemática sobre la educación y la cultura, enfatiza en su carácter antropológico, más allá de los discursos, prácticas y sistemas en los que se instituye el acto educativo, se interesa por conocer los rasgos humanos que lo hacen posible. De esta manera, estudia "el hecho de que el hombre empieza su vida como niño y que en cuanto ser extremadamente capaz de aprender y necesitado de formación depende por largo tiempo de ayudas pedagógicas" (Scheuerl, 1985, p. 13). Dice Londoño (2013) al respecto:

Podemos afirmar que el objeto fundamental de la pedagogía es la educación del ser humano, verdad aparentemente aceptada por todos pero poco profundizada en su importancia y alcances. En este sentido tendríamos que afirmar que la historicidad propia de la antropogénesis implica el crecimiento del ser humano a través de experiencias significativas que modifican la comprensión tanto de sí como de su relación con el mundo. La pedagogía 
no la podemos reducir a un discurso abstracto lógicamente construido, ideal y desarraigado de la realidad. Al contrario, su objeto es el estudio de la persona concreta, en una situación histórica definida y en contextos que de una u otra manera condicionan "el hacerse hombre" y los objetivos educativos que pretenden ayudarle a encontrar un sentido a su vida. (p. 29)

A diferencia de los animales que poseen una condición especializada, mediada por sus instintos, a través de los cuales preservan su vida natural en función de unas tareas predeterminadas; el hombre aparece en el mundo con una inespecificación orgánica y un primitivismo biológico (Gehlen, 1993). Con esto se reconoce que en el proceso evolutivo de la especie ni su anatomía ni su fisiología se han adaptado a un contexto específico, manteniéndose como un animal poco desarrollado y bastante frágil ante sus depredadores. Esto le representa la necesidad de aprender a ser, por lo cual ha de educarse y formarse, con el fin de no extraviarse en lo que le es impropio de acuerdo con su cultura. Solo el hombre puede considerarse ser excéntrico (Plessner, 2013) por su capacidad de salirse de su propio centro para indagar su vida de manera crítica y, a partir de allí, reorientar su existencia.

Esto confirma que "el hombre puede ser más o menos que un animal pero nunca un animal" (Scheuerl, 1985, p. 54), pues el espíritu que constituye su inteligencia práctica lo provee de

\section{[...] independencia, libertad o autonomía esencial -o la del centro de su existencia-frente a los lazos y la presión de lo orgánico, de la "vida". [...] Semejante ser "espiritual" ya no está vinculado a sus "impulsos", ni al mundo circundante, sino que es "libre frente al mundo circundante”, está abierto al mundo. (p. 64).}

En oposición al animal, cuya estructura fisiológica está determinada por y para el medio que habita, el hombre es capaz de una conducta que trasciende tal contexto, en ejercicio de su facultad para elegir y preferir. Él transforma la reproducción y la rigidez instintivas en creación y apertura para adaptarse a situaciones nuevas, no típicas de su especie. "El hombre es, según esto, la X cuya conducta puede consistir en 'abrirse al mundo' en medida ilimitada" (p. 66), lo cual quiere decir, justamente, que puede modelar su propia vida según su conciencia, libertad y voluntad.

\section{Las imágenes del hombre: fundamentos filosóficos de la antropología pedagógica}

La antropología pedagógica requiere entonces de una indagación filosófica sobre el hombre para erigir los rasgos humanos hacia los cuales se proyectan las acciones educativas y de realización de las personas. Esta elaboración surge en el seno de la antropología filosófica concebida por Scheler (1972) en los siguientes términos:

Ciencia fundamental de la esencia y de la estructura
esencial del hombre; de su relación con los reinos
de la naturaleza (inorgánico, vegetal, animal) y
con el fundamento de todas las cosas; de su origen
metafísico y de su comienzo físico, psíquico y espi-
ritual en el mundo; de las fuerzas y poderes que
mueven al hombre y que el hombre mueve; de las
direcciones y leyes fundamentales de su evolución
biológica, psíquica, histórico-espiritual y social, y
tanto de sus posibilidades esenciales como de sus
realidades. En dicha ciencia hállanse contenidos el
problema psicofísico del cuerpo y el alma, así como
el problema noético-vital. (p. 9)

Desde este fundamento, la antropología filosófica reflexiona sobre los hallazgos empíricos de las demás antropologías para consolidar una idea de hombre, que socialmente trasciende en ideal al que tácita o intencionalmente se aspira, proyectando una antropología pedagógica. "La pregunta por qué es el hombre pertenece a la antropología filosófica. Pero dentro de esta antropología filosófica, al centrarse en el homo educandus, se enfatiza en 'el hombre que se hace, en el niño y el adolescente'” (Dienelt, 1980, p. 39). Es decir, en la existencia en proceso continuo de convertirse en hombre: ese siendo constante en el que el carácter no fijado (potencia) deviene permanentemente en acto. En efecto, para alcanzar su realización, "el hombre necesita aprender a ser lo que es - y antes, saber lo que es - porque puede acabar "siendo", en su actuación, en su comportamiento, justamente lo que no es" (Barrio, 2010, p. 33). Esta autointerpretación le posibilita desarrollar determinadas cualidades, consolidando su ser y hacer en el mundo, de acuerdo con su apertura originaria.

No es de extrañar entonces que una parte considerable de la antropología pedagógica explore las imágenes del hombre recopilando las comprensiones sobre lo humano y sus aspiraciones consecuentes en diversos pueblos y épocas. Esto confirma la idea según la cual "todos los sistemas pedagógicos o hipótesis sistemáticas contienen una antropología pedagógica o tienden a ella" (Roth, 1966, citado por 
Scheuerl, 1985, p. 19), o, más puntualmente, que "toda pedagogía se basa en una antropología" (Bollnow, 1979, citado por Scheuerl, 1985, p. 16).

Este fue el esfuerzo reconstructivo que presentó Nohl (1981) en el primer libro publicado en Alemania sobre antropología pedagógica, Carácter y destino, en 1929. Allí, este pedagogo de las ciencias del espíritu estudia al hombre desde sus aspectos congénitos e inmutables hasta su desarrollo espiritual, modelado por las diversas formas de vida, articulando los aportes especialmente de filósofos, pedagogos y psicólogos en conexión con otras ciencias humanas. Por esta misma vía, Scheuerl (1985) parte de la paideia griega y la tradición presocrática y sofística para luego profundizar en las concepciones educativas y formativas de autores clásicos como San Agustín, Comenius, Rousseau, Pestalozzi, Kant, Herder, hasta los planteamientos contemporáneos de Nietzsche y Portmann, y los estudios antropológicos de Scheler, Hartmann, Plessner o Gehlen. Más recientemente, Hamman (1992) profundiza en los modelos clásicos (occidental-cristiano, dinamicista-biologista, marxista) y contemporáneos (antropobiología, conductista, cibernético, de análisis existencial) con este mismo fin de evidenciar estos ideales formativos a los que ha tendido la educación históricamente.

Dentro de la antropología pedagógica, el término imagen del hombre refiere, a veces indistintamente, a modelos o directrices que se pretenden alcanzar, al compendio de datos antropológicos de un momento histórico determinado, o a los análisis estructurales minuciosos sobre lo humano desde diversas disciplinas. Con el propósito de clasificar tales aproximaciones, Scheuerl (1985) distingue tres tipos de estudio antropológico: uno integrador, que busca agrupar todas las ciencias del hombre basado en la ambición de su comprensión total; otro analítico-existencial, basado en los aspectos inestables de la condición humana desde un abordaje fenomenológico; y finalmente, los estudios orientados a estas imágenes del hombre, como modelos sociales.

En cualquiera de estos grupos, la antropología pedagógica se debate entre la realidad empírica y los ideales de cada cultura pues, de acuerdo con Nohl (1981), más allá de hacer parte del gran campo del conocimiento del hombre en general, esta se orienta a la educación. Por ello, se enfoca en la realidad circunstancial de las personas, pero siempre apuntando a sus posibilidades axiológicas (valores) en cuanto aspiración a una vida superior. Para este autor, "el verdadero hombre solo se revela en la comprensión ideal, que es, además, la condición de toda comuni- dad pedagógica" (Nohl, 1981, p. 19), lo cual implica siempre abordarlo como posibilidad espiritual, trascendiendo sus limitaciones biológicas.

Sin embargo, en la actualidad ya no se trata de desplegar una ideología desde una concepción particular del ser humano, como directriz a seguir, sino de reelaborarla continuamente, de acuerdo con los avances de las ciencias del hombre (Saavedra, 2020b). Ciertamente,

[...] la antropología pedagógica viene a situarse en el límite en el que nos hemos de preguntar si la multiplicidad histórica de las situaciones no nos impide pronunciar definiciones antropológicas (por ejemplo, acerca "del niño", de "la educación", o de "la persona madura y adulta") relativizando de antemano todas las imágenes del hombre. (Scheuerl, 1985, p. 14)

Si el carácter abierto del ser humano abre múltiples posibilidades de realización, las cuales se consolidan como efectos que responden a la realidad cambiante y también plural a la que está expuesto en diversos nichos sociales, el mismo concepto de hombre está infinitamente reconstruyéndose, actualizándose.

De acuerdo con Dienelt (1980), para superar la preeminencia de estas imágenes predeterminadas, la antropología pedagógica estudia críticamente la experiencia humana de seres concretos, no idealizados, construyendo entonces tales imágenes a través de la experiencia real: "en el trato con las personas" según exigía Nohl (1981). En este proceso se devela que el hombre no solo afronta asuntos de supervivencia como los demás animales, sino que también está llamado a la construcción del sentido de su vida particular desde el ejercicio de su libertad. Este intento, desde una perspectiva existencial, configuraría la esencia del hombre: lo que cada persona es de manera única y singular. A su vez, tales conceptos plurales y en constante construcción conllevan una activa reflexión pedagógica sobre la educación y la formación basada en el destino del hombre y el sentido de su vida en particular, abordando a cada persona en sus propias circunstancias. "La formación en cuanto penetración espiritual, en cuanto interpretación del mundo, en cuanto hallazgo del sentido de la vida, representa una necesidad humana; de que la formación aparece, pues, como un medio de dominio de la existencia" (Dienelt, 1980, p. 337). Por esta razón, lo importante no está en instituir métodos o fórmulas para la instrucción, sino en crear interacciones y escenarios significativos que posibiliten el hallazgo de dicha orientación vital. 
En última instancia, el centro de atención de la antropología pedagógica es la formabilidad y la educabilidad del ser humano, por medio de las cuales encuentra o crea un sentido particular para su existencia en el marco de posibilidades dado por la cultura y la educación. En este entorno, el desbordamiento de sentidos que implica la formación (Vargas et al., 2010) lleva a las personas a trascender lo propuesto, tomando conciencia de sí y adueñándose de su existencia, a través del tejido de significaciones que constituye el mundus humano.

\section{El anthropos como un ser de mediaciones}

De acuerdo con el propósito de la antropología pedagógica de reelaborar constantemente la concepción del anthropos de acuerdo con los avances de las ciencias del hombre, para así enriquecer la reflexión pedagógica, y viceversa, a continuación establecemos un puente entre los fundamentos de la antropología de la comunicación (Duch y Chillón, 2012), la antropología filosófica (Scheler, 1960), la filosofía cultural (Cassirer, 2016) y la antropología cultural (Geertz, 2006), por una parte, y las ideas recientes de antropología pedagógica (Barrio, 2010; Vargas-Guillén et al., 2010), por otra, con el fin de actualizar las imágenes generales del hombre en la construcción singular, existencial, de sentido por parte de cada persona.

De acuerdo con Duch y Chillón (2012), el hombre es un ser de mediaciones, debido a que solo puede acceder al mundo a través de sus múltiples lenguajes, los cuales no se limitan a ser un medio de ingreso, sino que constituyen, a través de sus signos, símbolos y metáforas, la única realidad humana posible. En cuanto ser políglota, el anthropos recurre a diversos modos de expresión y representación, por lo cual no se reduce específicamente a una de sus mediaciones -Homo symbolicus, Homo sapiens, Homo logicus, Homo mythicus, Homo signans, Homo ridens, Homo faber, Homo Loquens- sino que hace del lenguaje su mediación constitutiva - "el lenguaje es la casa del ser", según célebre expresión de Heidegger (2013)pues a través de esta facultad exclusiva se crea a sí mismo y configura su mundo.

Por mor del lenguaje, ante todo, la "realidad humana" es creación radical, poiesis en sentido estricto. El anthropos poetiza e inventa sin cesar [...]. Es una criatura fabuladora que se conduce semiótica, imaginativa y estéticamente, y que gracias sobre todo al verbo -aunque no solo, añadimos nosotros- es capaz de erigir y esculpir el mundus que habita. (Duch y Chillón, 2012, p. 131).
A través del lenguaje el hombre no solo crea la realidad, sino que se despliega en ella, instituyendo la cultura como su segunda naturaleza (mundus), en cuanto entorno artificial que justamente lo aleja de la naturaleza pura (physis y bios) y le posibilita diversas maneras de realizarse desde un nicho social específico (Duch y Chillón, 2012). En consecuencia, todas sus producciones son una hechura, producto del empalabramiento de la realidad en el que se hace humano (Chillón, 2014).

Esta construcción de lo real, de la vida, de su mun$d u s$, solo es posible porque el hombre es un animal simbólico; esto es, porque posee una "facultad simbolizadora" que le permite generar formas simbólicas entendidas como diversas composiciones de lo que instituye como mundo. Tales creaciones del espíritu son el lenguaje, el arte, el mito o el conocimiento, según la filosofía cultural propuesta por Cassirer (2016). Sin aquellas, vivir se limitaría a existir biológicamente y no a la vida que, en términos humanos, solo puede constituirse mediante los procesos de significación, en la creación de símbolos. A través de ellos, el espíritu se articula con la materia, con ese ideal de lo puramente sensible, para construir la única realidad posible para el hombre. Así, además de sintetizar las oposiciones entre objetividad y subjetividad, entre espíritu y materia, entre interior y exterior, se instituye el mundo y la conciencia personal, construyendo la vida, su sentido.

En cuanto animal simbólico, el anthropos evidencia que solo puede constituirse a través de mediaciones. Esto lo hemos explorado con mayor detenimiento a través de tres perspectivas (Saavedra, 2020b): en primer lugar, desde la antropología filosófica (Scheler, 1960), que sitúa el lugar metafísico y privilegiado del hombre en el cosmos basado en la manifestación en él del espíritu. En segundo lugar, desde la filosofía cultural (Cassirer, 2016) y la consecuente antropología de la comunicación (Duch y Chillón, 2012), porque su única manera de conocer (crear) la realidad es a través de las formas espirituales. Finalmente, desde las antropologías pedagógica (Barrio, 2010) y cultural (Geertz, 2006), porque su ser carente biológicamente requiere de la cultura y de la educación, en cuanto mediaciones simbólicas, para consolidarse como humano, para llegar a ser hombre. Se trata, evidentemente, de tres caminos para llegar al mismo lugar, aquel en el que la proyección espiritual del hombre se consolida en su creación por excelencia: la cultura, que a su vez lo lleva a crearse a sí mismo.

Debido a que el hombre se define como creador de formas espirituales, la primera perspectiva permite concebir a la persona como "centro activo en que el 
espíritu se manifiesta dentro de las esferas del ser finito" (Scheler, 1960, p. 63). Esto evidencia que más allá de los grados del ser psicofísico (el impulso afectivo de la planta, la conducta instintiva y la memoria asociativa de los animales, hasta llegar a la inteligencia práctica de estos en un nivel superior) en los que el hombre ocupa esta última, máxima escala; su esencia y su puesto en el cosmos no están relacionados con su inteligencia y capacidad de decisión consecuente, sino dados por su extensión metafísica, por su espíritu. De acuerdo con la célebre definición de Scheler (1960), este principio se opone a la vida natural dado que engloba los procesos de la razón, "la intuición de fenómenos primarios o esencias, y además una determinada clase de actos emocionales y volitivos" (p. 65). El hombre, entonces, no está configurado exclusivamente por el medio que habita, sino que sus carencias y falta de especialización biológicas, ahora afrontadas desde el espíritu, constituyen su apertura al mundo, mediante la cual trasciende sus limitaciones contextuales a partir de la síntesis de lo real y de sí mismo en un proceso de objetivación.

Para el animal, en cambio, no hay "objetos". El animal vive extático en su mundo ambiente, que lleva estructurado consigo mismo adonde vaya, como el caracol su casa. El animal no puede llevar a cabo ese peculiar alejamiento y sustantivación que convierte un "medio" en "mundo"; ni tampoco la transformación en "objeto" de los centros de "resistencia", definidos afectiva e impulsivamente. Yo diría que el animal está esencialmente incrustado y sumido en la realidad vital correspondiente a sus estados orgánicos, sin aprehenderla nunca "objetivamente". La objetividad es, por tanto, la categoría más formal del lado lógico del espíritu. (Scheler, 1960, p. 67).

Más allá de la conciencia también existente en el animal, el hombre desarrolla conciencia de sí, lo cual le permite manejar sus impulsos. De esta manera, no solo puede

\section{[...] elevar el "medio" a la dimensión de "mundo" y hacer de las "resistencias" "objetos", sino que puede también -y esto es lo más admirable- convertir en objetiva su propia constitución fisiológica y psíquica. Solo por esto puede modelar libremente su vida. (Scheler, 1960, p. 68)}

El anthropos objetiva el mundo y a sí mismo. Al hacerlo, se eleva por encima de su ser y de la realidad convirtiendo todas las cosas y seres en objetos de conocimiento, de manera que proyecta una nueva dimensión de lo real a partir de formas espirituales, entre las cuales el lenguaje y la cultura ocupan un lugar fundamental.
Justamente, la segunda perspectiva enfatiza en el papel del lenguaje, no como envoltura de lo real, vehículo del pensamiento o representación de los objetos del mundo, sino como la forma espiritual constitutiva de la realidad. Sus diversas manifestaciones no se proponen como copias de lo real externo predado, sino que "representan las grandes direcciones de la trayectoria espiritual, del proceso ideal en el cual se constituye para nosotros la realidad como única y múltiple" (Cassirer, 2016, p. 71). Es decir, cada expresión lingüística es comprendida no como objeto en sí ni como una copia burda de la realidad, sino como signo cuyo valor está en su significación independiente. Esta contiene la forma espiritual en que el hombre crea la realidad, lo cual le facilita realizar conexiones con otros signos, así como "hacer presente lo ausente, lo ausente pretérito y también lo ausente por venir" (Chillón, 2010), trascendiendo la inmediatez de lo físico, esto es, configurando su conciencia.

La conclusión antropológica de esta segunda perspectiva es que, más allá del poliglotismo o la diversidad cultural, es rasgo distintivo del ser humano su facultad simbolizadora, lo simbólico, mediante lo cual construye su mundus basado en la unión entre materia y espíritu. Aún más, esto conlleva entender, de acuerdo con Cassirer (2016), que el hombre se crea a sí mismo mediante la palabra y, por tanto, es en sí mismo una forma simbólica, mediado por su cualidad de ser libre, no determinado, aunque condicionado por leyes naturales y sociales.

Esto remite a la tercera perspectiva, que considera al hombre como "un animal inserto en las tramas de significación que él mismo ha tejido", su cultura (Geertz, 2006, p. 20). Esta, además de sistema semiótico, cumple la función de controlar su conducta, dado que es justamente el hombre el animal que depende de ayudas extragenéticas para ordenar su vida y gobernarse. De este modo, como ya lo argüía la antropología pedagógica, no es posible definir al ser humano exclusivamente desde sus aptitudes innatas, sino que en relación con ellas se ha de atender a estos sistemas de significación que logra crear como expresión de su espíritu. La cultura, entonces, es parte constitutiva del ser humano en cuanto serie de dispositivos simbólicos o fuentes extrasomáticas de información que le indican lo que debe ser, cómo debe comportarse. "Llegar a ser humano es llegar a ser un individuo y llegamos a ser individuos guiados por esquemas culturales, por sistemas de significación históricamente creados en virtud de los cuales formamos, ordenamos, sustentamos y dirigimos nuestras vidas" (Geertz, 2006, p. 57). 
En respuesta a su insuficiencia biológica, que no le permite adaptarse a un medio específico para existir, el hombre adapta cualquier contexto a sus propias necesidades a través de su creación fundamental, la cultura. Esta, además de consolidar la distancia entre él y la naturaleza, proyecta un sistema semiótico que busca modelar "una serie de conductas relativamente coherentes, que den estabilidad y firmeza al comportamiento humano, facilitando que este pueda ajustarse a la índole peculiar del ser del hombre, que es la propia de un híbrido psicobiológico" (Barrio, 2010, p. 105). A través de este entramado simbólico el hombre mismo se transmite hábitos, saberes, tecnologías y modos de ser para la conservación de la especie, a partir del reconocimiento de su precariedad instintiva.

El hombre necesita tanto de esas fuentes simbólicas de iluminación para orientarse en el mundo, porque la clase de fuentes no simbólicas que están constitucionalmente insertas en su cuerpo proyectan una luz muy difusa. Los esquemas de conducta de los animales inferiores, por lo menos en mucha mayor medida que en el hombre, les son dados con su estructura física; las fuentes genéticas de información ordenan sus acciones dentro de márgenes de variación mucho más estrechos y que son más estrechos en cuanto más inferior es el animal. En el caso del hombre, lo que le está dado innatamente son facultades de respuesta en extremo generales que, si bien hacen posible mayor plasticidad, mayor complejidad y, en las dispersas ocasiones en que todo funciona como debería, mayor efectividad de conducta, están mucho menos precisamente reguladas. Y esta es la segunda fase de nuestra argumentación: si no estuviera dirigida por estructuras culturales -por sistemas organizados de símbolos significativos-, la conducta del hombre sería virtualmente ingobernable, sería un puro caos de actos sin finalidad y de estallidos de emociones, de suerte que su experiencia sería virtualmente amorfa. La cultura, la totalidad acumulada de esos esquemas o estructuras, no es solo un ornamento de la existencia humana, sino que es una condición esencial de ella. (Geertz, 2006, p. 52)

Así pues, el anthropos es inconcebible sin mediaciones y, por tanto, solo puede constituirse a través de la palabra, del símbolo, del artificio cultural. "De ahí que la cultura sea, no solo compensadora de la naturaleza humana sino, en rigor, parte de ella", como "el modo propio y natural del bios humano, el ingrediente más específico de su 'biocenosis'” (Barrio, 2010, p. 104, énfasis del original). Esto constata el papel ontológico del lenguaje debido a que, para lograr conocer el mundo, el hombre lo abstrae, bautiza y representa, simbolizándolo, humanizándolo. Por esta misma vía, se nombra a sí mismo, haciéndose objeto de meditación, representándose lo que es y lo podría ser a partir de un proceso autorreflexivo que le permite dirigir su propia existencia.

La realidad humana solo es posible en el lenguaje, pues lo real solo es tal para el hombre si le da un nombre, a partir del cual da existencia a aquello que puede pensar, entender, reflexionar, como una "síntesis no dada anteriormente del 'yo' y el 'mundo"” (Cassirer, 2016, p. 35). Este entrelaza el aspecto fónico con la dimensión semántica para construir sentido. Así se construyen los hechos, que no son otra cosa que constructos sémicos que el hombre teje y comunica. Justamente Gadamer (1992) ha desarrollado el concepto de lingüisticidad a partir de los planteamientos de Humboldt y Herder, profundizando que tanto el hombre como el mundo están inmersos en el lenguaje. "Aprender a hablar no significa utilizar un instrumento ya existente para clasificar el mundo familiar y conocido, sino que significa la adquisición de la familiaridad y el conocimiento del mundo mismo tal como nos sale al encuentro" (Gadamer, 1992, p. 148). Su investigación reafirma que el ser humano está mediado por la interpretación lingüística.

Por lo demás, toda forma simbólica pone de manifiesto la condición ambigua del ser humano, ese "ser anfibio en el que lo ingénito y pre-dado - la fisiología, el instinto, los genes- integra el sustrato sobre el que medra lo artificial y adquirido - la historia, la cultura y los memes-" (Chillón, 2010, p. 20). Y es que, no importa la perspectiva en la que se piense la experiencia humana, esta se encuentra en puntos intermedios e inestables entre la determinación y la libertad, la estructura biológica y su actualización biográfica, lo natural y lo cultural, sus ansias de infinitud desde su finitud insoslayable, sus proyecciones espirituales en medio de sus necesidades fisiológicas. Aunque esta condición podría asumirse inicialmente como deficiencia por las incomodidades e inconformidades asociadas a la indeterminación, dentro de la reflexión pedagógica constituye el mayor potencial de la especie, pues implica que no existe una fórmula infalible para vivir. Tal responsabilidad recae en el hombre y sus elecciones ante los dilemas existenciales. En consecuencia, él puede rehacer su vida cuando quiera.

Así pues, la antropología pedagógica constata y recrea esta condición ambigua del hombre entre su ser (imagen) y su devenir (sentido). El lenguaje como forma espiritual hecha cultura prescribe tradiciones y enseñanzas que se transmiten mediante la educación, queriendo mostrar al hombre lo que ha de ser en cada nicho social específico. Simultáneamente, configura 
su conciencia, a través de la cual él podrá reaccionar a la educación para tomar decisiones singulares gracias a su formabilidad distintiva.

\section{La formación como construcción de sentido}

A partir de la idea de cultura como esquema de conducta humana, la educación posibilita una experiencia significativa en el nicho social al cual el niño llega al nacer, desde su contexto familiar hasta la escuela, atravesando todos los ámbitos externos que procuran acogerlo y legarle una manera de ser y de vivir. Por su parte, la formación es su desbordamiento interior, el despliegue de sus posibilidades, que evidencia una respuesta propia-conciencia, voluntad, toma de postura, autonomía- y que, en cuanto tal, trasciende lo propuesto por tales acciones educativas, para construir un sentido personal. La formación se refiere al trabajo sobre sí mismo para forjar el hombre al que se aspira, contenido en uno mismo como deseo y posibilidad de existencia, el cual debe desplegarse, desbordarse, convertirse, transformarse (Saavedra, 2017, 2020a).

En este proceso, el lenguaje como su mediación fundamental, así como instituye parámetros culturales que lo orientan en el mundo, permite al anthropos adquirir conciencia de sí, proyectando su existencia a través de realidades hechas de palabras. Tan solo la presunción de un pasado o un futuro -irrealidades solo existentes en la mente del hombre gracias al lenguaje- le permite comprenderse a sí mismo y proyectarse, de acuerdo con su apertura al mundo.

Lo que aún no es forma parte importante de lo que el ser humano es. En efecto, en una medida no pequeña, todo hombre es lo que ha llegado a ser (a partir de lo que fue y ya no es) y lo que aspira a ser y todavía no ha logrado ser. La descripción de esos dos sectores de lo irreal forma parte de la realidad de lo que cada ser humano es. (Barrio, 2010, p. 114)

Esto ilustra, sin duda, una manera en la que el lenguaje constituye la formación, es decir, la humanización, en cuanto desbordamiento de sentidos.

Precisamente, en La humanización como formación, Vargas-Guillén et al. (2010) plantean una actualización del concepto de formación en el intento de responder a la pregunta "¿Para qué formar a la persona humana?", desde la fenomenología y la antropología pedagógica. Con este propósito, parten de la definición de Heidegger, quien afirma que formar es "poner en libertad el ser en la comparecencia del ente mismo". Esto es ampliado por el autor en los siguientes términos:
Precisamente la formación es un poner en libertad al ser en su ahí, es la habilitación del Dasein no solo para que se ex-ponga, sino para que en su "lenguajear" ponga de manifiesto -en ex-posición- al ser mismo. Entonces la formación no es una estrategia para imponer un carácter o para marcar, sino que es un salto en sí que el ser da en su ahí-en cuanto ente en el que se ex-pone-; mediante este "salto" tanto el ahí como lo manifestado en el ahí dan un paso fuera de sí [...] (Heidegger, 1967, p. 7). Queda así al descubierto que es el lenguaje -y no el ser, como tampoco es el hombre- el que abre el mundo, el que y en el que se despliega el ser. (p. 14)

La formación es entonces un acto de desbordamiento del ser por medio del lenguaje, que es el único medio en el cual puede exponer (expresar) sus posibilidades de existencia y, de esta manera, formarse.

La formación es un proyecto de desbordamiento [...]. No hay quien que pueda ser "productor de sentido"; pero no es que lo quiera o no lo quiera; es que su posición de ahí del ser, su ser Dasein, le impone una potencia de despliegue. Y la renuncia a su mismidad es, así mismo, el mantenerse en las márgenes, en los bordes; en cambio, el apropiarse de las propias posibilidades expresivas es un desbordamiento, una marginación, un salto fuera de la corriente de lo siempre mismo, que se repite hasta la abulia [...]. Así pues, la inmersión en el carácter Sein del Dasein impone romper la margen, desbordar, desplegar el sentido. (Vargas-Guillén et al., 2010, p. 35)

Desde esta perspectiva, estos autores concluyen que la formación consiste en "poner en libertad el ser" de cada quien hasta que este pueda "hacer comparecer en la forma justa al ente mismo", no como proyecto sino en cuanto sentido destinal. Esta no es una verdad que debe ser repetida, sino una interpretación constante que se reconstruye desde el desbordamiento. Más allá de las prácticas de instrucción, cada persona está siendo constituida por efectos de formación, dado que los parámetros inducidos en la cultura siempre se discuten y reconstruyen desde el despliegue de sentido.

La pedagogía se asume entonces como proyecto de formación que es, en últimas, "un problema filosófico del sentido con el que los seres humanos dan contenido a sus horizontes de ser, en la construcción de sus proyectos individuales y colectivos" (Vargas-Guillén et al., 2010, p. 59). Esto es, la búsqueda del sentido de la vida por parte de cada quien, según los aportes de Frankl a la Antropología pedagógica de Dienelt (1980). Esto implica que la pedagogía no debe desarrollar discursos universales sobre las personas, sino procurar que ellos mismos se narren, construyendo, proyectando, 
compartiendo y enriqueciendo sus visiones de mundo, para formarse (Saavedra, 2020b). Así, la antropología pedagógica termina problematizando la idea de autorrealización propia de la Bildung como referente fundamental de la formación, la cual ha tenido múltiples resonancias en modelos de educación no directiva como los de Montessori o Müller-Eckhard, este último centrado en la premisa pedagógica "ser sin angustia lo que se es". Aunque esta visión provee elementos esenciales para dar cuenta de que la acción educativa no puede limitarse a la instrucción en habilidades o a la transmisión de saberes especializados desde el exterior, enfatizando en las respuestas del hombre ante lo propuesto; resulta cuestionable abandonar a la persona en su libertad y crecimiento porque puede caer en lo relativo y lo arbitrario, develando lo que $y a$ es o lleva en su interior. De acuerdo con Dienelt (1980),

[...] nuestra tarea ha de ser más bien la de crear los supuestos necesarios para que el niño llegue a ser lo que puede y debe llegar a ser. El yo no le está "dado" simplemente al hombre, sino ofrecido, "propuesto" en realidad "como una obra posible, como una región a conquistar, la obra maestra de su vida". (p. 262)

Esta tarea educativa refiere a un concepto de formación en el que uno mismo y lo otro ya no se conciben enfrentados como interior y exterior, sino que se amalgaman en un proceso dialéctico, una enajenación de sí mismo en lo otro que termina con la vuelta enriquecida a sí mismo. En consecuencia, resulta impensable que el sentido del hombre resida en él mismo de manera espontánea y que el trabajo educativo atienda meramente a dejar que aparezca. De hecho, "el sentido de la vida difiere de un hombre a otro, de un día a otro, de una hora a otra", pues refiere al descubrimiento de un "sentido concreto de la vida de un individuo en un momento determinado" (Frankl, 2004, p. 131). Lo que buscan las acciones intencionadas es espolear efectos en las personas. Así la idea de autorrealización espiritual de la tradición pedagógica alemana se actualiza en la de búsqueda de sentido. Esto implica, también para la antropología pedagógica, una actualización realista y constante de aquellos valores por los que cada quien opta en su vida según sus propias circunstancias, en relación dialéctica con un amplio panorama de imágenes del hombre.

La autorrealización individual no es algo que se verifique al hilo del crecimiento, ni se desenvuelva a partir de una disposición natural de su estructura ni a partir de condiciones sociales previamente dadas, sino que se deriva de un obrar no siempre en verdad consciente y reflexivo, pero decisivo a pesar de todo (en la conciencia). El individuo ciertamente se impone y se eleva por su propio esfuerzo hasta una relación (dialéctica) frente al mundo que le es dado en cada caso y, de este modo, "propuesto". Pero cuando se designa la "génesis de la persona" como "historia individual de la conciencia" (Derbolav), aquí entendemos esto ya como una "historia individual desde la conciencia”. (Dienelt, 1980, p. 232)

Evidentemente, Dienelt (1980), como deudor de la logoterapia propuesta por Frankl, critica el potencionalismo propio de las teorías de la autorrealización (ese desplegar espontáneo de las capacidades propias), debido a que tal desarrollo solipsista olvida el mundo y sus posibilidades de sentido y de valor; aspectos fundamentales de la formación en cuanto encuentro con el otro y con lo otro. De acuerdo con Frankl:

Pues si se me hace creer que soy sin más (y lo que he sido ya siempre) aquello que, sin embargo, tan solo debo llegar a ser, me sustraigo al tormento de la elección, se me ahorra ciertamente el tener que decidir siempre y en cada caso cuál de las posibilidades debo desechar, dejándola simplemente sin realizar, y cuál de entre ellas debo perpetuar realizándola. (1961, p. 219, citado por Dienelt, 1980, p. 267)

Desde esta perspectiva, la autorrealización se presenta "como efecto de la realización de valores y del cumplimiento de sentido, pero no como fin de lo mismo" (Dienelt, 1980, p. 270). En otras palabras, la formación es un proceso efectual que busca la realización basada en la tensión -que estos autores recalcan y que aquí se suscribe- entre la individualidad personal y los valores sociales, entre lo que un hombre es y lo que ha de llegar a ser, entre su imagen predeterminada y su existencia particular, esto es, entre ser y sentido. En este contexto, la antropología pedagógica configura un escenario y un encuentro con los otros y lo otro que de manera intencionada inste a la persona a tomar decisiones para obrar su vida, haciéndose consciente y responsable de su libertad para transformarse.

\section{Referencias}

Aranguren, J. (2004). La idea de formación. Pensamiento y Cultura, 7, 33-46.

Ávila, R. (1990). ¿Qué es pedagogía? Bogotá: Nueva América.

Ávila, R. (1994). La educación y el proyecto de la modernidad. Bogotá: Anthropos.

Barrio, J. (2010). Elementos de antropología pedagógica. Madrid: Rialp.

Bollnow, O. (2005). Principios metódicos de la antropología pedagógica. Educación y Pedagogía, 8(42), 77-80. 
Campo, R. y Restrepo, M. (2000). Del control a la búsqueda de sentido. Revista Javeriana, 134, 169-175.

Cassirer, E. (2016). Filosofía de las formas simbólicas. I. El lenguaje. México: Fondo de Cultura Económica.

Chillón, A. (2010). La condición ambigua. Diálogos con Lluís Duch. Barcelona: Herder.

Chillón, A. (2014). La palabra facticia. Literatura, periodismo y comunicación. Barcelona: Universidad Autónoma de Barcelona.

Dienelt, K. (1980). Antropología pedagógica. Madrid: Aguilar.

Dilthey, W. (1940). Fundamentos de un sistema de pedagogía. Buenos Aires: Losada.

Duch, Ll. y Chillón, A. (2012). Un ser de mediaciones. Antropología de la comunicación. Vol. 1. Barcelona: Herder.

Durkheim, É. (2001). Educación y sociología. México: Coyoacán.

Echeverri, J. (ed.) (2001). Encuentros pedagógicos transculturales: desarrollo comparado de las conceptualizaciones y experiencias pedagógicas en Colombia y Alemania. Medellín: Universidad de Antioquia.

Echeverri, J. (2013). Un campo conceptual y narrativo de la pedagogía [ponencia]. Memorias Congreso de Investigación Y Pedagogía, Universidad Pedagógica y Tecnológica de Tunja (UPTC).

Fabre, M. (2011). Experiencia y formación: la Bildung. Educación y Pedagogía, 23(59), 215-225.

Flórez Ochoa, R. (2001). Hacia una pedagogía del conocimiento. Bogotá: McGraw-Hill.

Frankl, V. (2004). El hombre en busca de sentido. Barcelona: Herder.

Gadamer, H. (1992). Verdad y método II. Salamanca: Sígueme.

Gadamer, H. (2012). Verdad y método. Salamanca: Sígueme.

Garcés, J. y Runge, A. (2011). Educabilidad, formación y antropología pedagógica: repensar la educabilidad a la luz de la tradición pedagógica alemana. Revista Científica Guillermo de Ockham, 9(2), 13-25.

Geertz, C. (2006). La interpretación de las culturas. Barcelona: Gedisa.

Gehlen, A. (1993). Antropología filosófica. Del encuentro y descubrimiento del hombre por sí solo. Barcelona: Paidós.

Hamman, B. (1992). Antropología pedagógica. Introducción a sus teorías, modelos y estructuras. Madrid: Vicens Vives.
Heidegger, M. (2013). Carta sobre el humanismo. Madrid: Alianza.

Herbart, J.F. (1990). Pedagogía general. Barcelona: Ediciones de la Lectura.

Horlacher, R. (2014a). Bildung. La formación. Barcelona: Octaedro.

Horlacher, R. (2014b). ¿Qué es Bildung? El eterno atractivo de un concepto difuso en la teoría de la educación alemana. Pensamiento Educativo. Revista de Investigación Educacional Latinoamericana, 1(51), 35-45.

Ipland, J. (1999). El concepto de Bildung en el neohumanismo alemán. Huelva: Hergué.

Jaeger, W. (2001). Paideia: los ideales de la cultura griega. México: Fondo de Cultura Económica.

Kant, I. (2008). Sobre pedagogía. Córdoba: Encuentro.

Larrosa, J. (2013). La experiencia de la lectura. Estudios sobre literatura y formación. México: Fondo de Cultura Económica.

Londoño, E. (2013). La antropología pedagógica comprometida con la humanización frente a los inhumanos procesos políticos, sociales y educativos. En J. Giraldo et al., Humanismo en debate 1 (pp. 27-50). Bogotá: Universidad de San Buenaventura.

Luzuriaga, L. (1991). Pedagogía. Buenos Aires: S.A.

Noguera, C. (2012). El gobierno pedagógico. Del arte de educar a las tradiciones pedagógicas. Bogotá: Siglo del Hombre Editores.

Noguera, C. (2008). Presentación. En A. Runge (2008), Ensayos sobre pedagogía alemana (pp. 9-14). Bogotá: Universidad Pedagógica Nacional (UPN).

Noguera, C. y Parra, G. (2015). Pedagogización de la sociedad y crisis de la educación. Elementos para una crítica de la(s) crítica(s). Pedagogía y Saberes, 43, 69-78. https://doi.org/10.17227/01212494.43pys69.78

Nietzsche, F. (2002). La gaya ciencia. Madrid: Edaf.

Nohl, H. (1981). Antropología pedagógica. México: Fondo de Cultura Económica.

Plessner, H. (2013). La risa y el llanto. Investigación sobre los límites del comportamiento humano. Madrid: Trotta.

Runge, A. (2008). Ensayos sobre pedagogía alemana. Bogotá: Universidad Pedagógica Nacional (UPN).

Saavedra, L. (2016). De la educación como sistema a la formación del ser humano. En A. Bejarano (ed.), Perspectivas de investigación. Una mirada desde la antropología pedagógica (pp. 37-51). Bogotá: Universidad de San Buenaventura. 
Saavedra S. (2017). Formación (Bildung) y creación literaria: "llegar a ser lo que se es" en diversos mundos posibles. La Palabra, 31, 197-210.

Saavedra, L. (2020). Incidencia de la evaluación en la formación de niños. Bogotá: Aula de Humanidades.

Saavedra, S. (2020a). Formación (Bildung) literaria basada en la creación de ficción. Folios, 51, 3-16.

Saavedra, S. (2020b). Creación literaria y formación humana. Una propuesta de antropología pedagógica. Bogotá: Aula de Humanidades.

Saavedra, L. y Saavedra, S. (2013). Entre lo deseable y lo realizable: didáctica, currículo y evaluación. En L. Niño Zafra (comp.), Currículo y evaluación críticos: Pedagogía para la autonomía y la democracia. Bogotá: Universidad Pedagógica Nacional (UPN).

Saavedra L. y Saavedra S. (2017). Formar maestros desde el devenir conceptual de la pedagogía. Tequio, 1, 50-55.

Scheler, M. (1960). El puesto del hombre en el cosmos. Buenos Aires: Losada.

Scheler, M. (1972). El saber y la cultura. Buenos Aires: La Pléyade.
Scheuerl, H. (1985). Antropología pedagógica. Barcelona: Herder.

Spranger, E. (1935). Las ciencias del espíritu y la escuela. Madrid: Publicaciones de la Revista de Pedagogía.

Vargas-Guillén, G. Gamboa, S., Reeder, H. (2010). La humanización como formación. La filosofía y la enseñanza de la filosofía en la condición postmoderna. Bogotá: San Pablo.

Vierhaus, R. (2001). Formación (Bildung). Educación y Pedagogía, (separata), 7-68.

Vilanou, C. (2001). De la paideia a la Bildung; hacia una pedagogía hermeneútica. Revista Portuguesa de Educaçao, 2(14), 3-30.

Wulf, C. (1985). El sueño de la educación. Educación. Colección semestral de aportaciones alemanas recientes en las ciencias de la educación, 31, 7-27.

Zuluaga, O., Echeverri, A., Martínez, A., Quiceno, H., Saenz, J., y Álvarez, A. (2003). Pedagogía y epistemología. Bogotá: Cooperativa Magisterio. 